\title{
Hytrosavirus genetic diversity and eco- regional spread in Glossina species
}

Irene K. Meki ${ }^{1,2}$, Henry M. Kariithi ${ }^{1,3}$, Mehrdad Ahmadi ${ }^{1,4}$, Andrew G. Parker ${ }^{1}$, Marc J. B. Vreysen ${ }^{1}$, Just M. Vlak ${ }^{2}$, Monique M. van Oers ${ }^{2}$ and Adly M.M. Abd-Alla ${ }^{1 *}$

\begin{abstract}
Background: The management of the tsetse species Glossina pallidipes (Diptera; Glossinidae) in Africa by the sterile insect technique (SIT) has been hindered by infections of G. pallidipes production colonies with Glossina pallidipes salivary gland hypertrophy virus (GpSGHV; Hytrosaviridae family). This virus can significantly decrease productivity of the G. pallidipes colonies. Here, we used three highly diverged genes and two variable number tandem repeat regions (VNTRs) of the GpSGHV genome to identify the viral haplotypes in seven Glossina species obtained from 29 African locations and determine their phylogenetic relatedness.
\end{abstract}

Results: GpSGHV was detected in all analysed Glossina species using PCR. The highest GpSGHV prevalence was found in G. pallidipes colonized at FAO/IAEA Insect Pest Control Laboratory (IPCL) that originated from Uganda (100\%) and Tanzania (88\%), and a lower prevalence in G. morsitans morsitans from Tanzania (58\%) and Zimbabwe (20\%). Whereas GpSGHV was detected in 25-40\% of G. fuscipes fuscipes in eastern Uganda, the virus was not detected in specimens of neighboring western Kenya. Most of the identified 15 haplotypes were restricted to specific Glossina species in distinct locations. Seven haplotypes were found exclusively in G. pallidipes. The reference haplotype H1 (GpSGHV-Uga; Ugandan strain) was the most widely distributed, but was not found in G. swynnertoni GpSGHV. The 15 haplotypes clustered into three distinct phylogenetic clades, the largest contained seven haplotypes, which were detected in six Glossina species. The G. pallidipes-infecting haplotypes H10, H11 and H12 (from Kenya) clustered with H7 (from Ethiopia), which presumably corresponds to the recently sequenced GpSGHVEth (Ethiopian) strain. These four haplotypes diverged the most from the reference H1 (GpSGHV-Uga). Haplotypes $\mathrm{H1}, \mathrm{H} 5$ and $\mathrm{H} 14$ formed three main genealogy hubs, potentially representing the ancestors of the 15 haplotypes.

Conclusion: These data identify G. pallidipes as a significant driver for the generation and diversity of GpSGHV variants. This information may provide control guidance when new tsetse colonies are established and hence, for improved management of the virus in tsetse rearing facilities that maintain multiple Glossina species.

Keywords: Salivary gland hypertrophy virus, GpSGHV, Genetic diversity, Sterile insect technique, Glossinidae, Tsetse, Virus evolution, Haplotype

\section{Background}

Management of insect vectors using the sterile insect technique (SIT) within the context of area-wide integrated pest management (AW-IPM) approaches, requires mass-production of high quality insects that must outcompete wild males for mating virgin wild females [1]. These non-viable matings eventually lead to the

\footnotetext{
* Correspondence: a.m.m.abd-alla@iaea.org

${ }^{1}$ Insect Pest Control Laboratory, Joint FAO/IAEA Programme of Nuclear Techniques in Food and Agriculture, International Atomic Energy Agency, Vienna International Centre, P.O. Box 100 1400, Vienna, Austria Full list of author information is available at the end of the article
}

decline of the target insect population and reduction in the occurrence of the trypanosomosis disease they transmit to animals and human. The successful eradication of a population of the tsetse fly species Glossina austeni Newstead (Diptera; Glossinidae) on Unguja Island in Zanzibar, using an AW-IPM approach with an SIT component [2] elicited efforts to apply a similar approach to eradicate G. pallidipes from the Southern Rift Valley region of Ethiopia [3]. However, like in many insect mass-production facilities where viral diseases challenge production of high quality insects [4], infections of G. pallidipes colonies with the Glossina pallidipes salivary 
gland hypertrophy virus (GpSGHV; Hytrosaviridae family) hindered full implementation of the SIT component of the Ethiopian program $[5,6]$.

The inbreeding in long-term colonized insects reduces their genetic diversity, i.e. fly populations become genetically more and more homozygous [7], which in return may promote their susceptibility to pathogen infections. Transmission, mainly horizontal, is further stimulated by the close interactions of tsetse conspecifics, the membrane feeding regimes, and the conducive environments created by the high densities in tsetse mass-production facilities [8]. Altogether these factors result in life-history trade-offs between immune and reproductive functions, which in turn contribute to reduced fitness-related traits of individual insects and colony productivity at large $[9,10]$. In nature, where tsetse flies blood-feed on live animals, the observed GpSGHV infections are largely asymptomatic. This could be due to the low population densities and solitary habitats of different tsetse species, which underscores the triggering of SGH in the field or simply due to the short life span of symptomatically infected flies which minimizes the chances of detecting the SGH. [6, 11-13].

Currently, two GpSGHV strains induce distinctive pathologies in G. pallidipes flies, one in the mass-rearing facility at Kaliti in Ethiopia (Ethiopian strain with high SGH prevalence), and the other at the FAO/IAEA Insect Pest Control Laboratory (IPCL) in Seibersdorf, Austria (Ugandan strain with low SGH prevalence) [11]. It is not known why GpSGHV infections have such a devastating impact only on colonized G. pallidipes, despite the rearing of this species together with multiple Glossina species in the same tsetse production facilities. Kariithi et al., [14] reported that GpSGHV-infected G. m. morsitans expressed more antiviral proteins than symptomatically infected $G$. pallidipes flies. For example, the reactive oxygen species and components of the phagocytic engulfment system were among the overexpressed proteins in G. m. morsitans. The expression of such antiviral proteins in $G M$. morsitans and the reduced expression these genes in symptomatically infected G. pallidipes indicates that this G. pallipides is immunocompromised in its response to GpSGHV. Being the most susceptible species to GpSGHV, one may hypothesize G. pallidipes as a key species that drives the evolution and the inter-species spread of GpSGHV in tsetse mass rearing facilities.

To manage the prevalence of SGH in tsetse mass-production facilities, it is necessary to understand the diversity, evolution and transmission potential of GpSGHV in Glossina species. Kariithi et al. [15] reported 23 GpSGHV haplotypes in wild G. pallidipes flies, but the virus' genetic heterogeneity found in that study was low, and without direct correlation to geographical locations. The GpSGHV diversity in other Glossina species has yet to be investigated. A high prevalence of both asymptomatic and symptomatic GpSGHV infections in G. pallidipes may increase the potential of cross-species exposure and transmission of the virus in mass-rearing facilities where multiple tsetse species are reared. Replication of viruses in a new host species may provide opportunities for the virus to adapt and evolve into novel viral haplotypes that may be more pathogenic, due to accumulated mutations over time. For instance, Grubaugh et al. [16] recently demonstrated that the genetic diversity of West Nile virus (WNV) depended on the mosquito species. The study demonstrated that the southern house mosquito, Culex quinquefasciatus Say supported the evolution of WNV variants exhibiting greater fitness when transferred to avian hosts compared to three other Culex species. The study concluded that $C$. quinquefasciatus is the main engine that drives WNV evolution. Although the study involved an RNA virus, the same dynamics may apply to evolution of DNA viruses such as GpSGHV, though most likely at much slower evolutionary rates.

In this study, we investigated the GpSGHV genetic diversity and prevalence in seven Glossina species obtained from different geographical locations throughout Africa. Based on comparison of the genomes of the two pathogenic strains GpSGHV-Uga and GpSGHV-Eth [16], the three highly diverged GpSGHV genes were selected, as well as two variable number tandem repeat regions (VNTRs) and these were used to construct phylograms and to search for the ancestor of this hytrosavirus. Our data are important for future development of robust strategies to effectively manage GpSGHV infections and sustainably remove SGHV from tsetse mass-rearing facilities.

\section{Results}

Prevalence of GpSGHV infection in wild Glossina species GpSGHV prevalence was tested for 3229 flies collected from 29 geographical locations and belonging to seven tsetse species (Table 1). The GpSGHV prevalence of some of the G. pallidipes individuals used in the current study was previously reported by Kariithi et al. [15]. In the current study, we extended the number of sampling locations and included other Glossina species. GpSGHV prevalence was determined by PCR amplifications of two conserved viral genes the odv-e66 (SGHV005) and dnapol (SGHV079) which were not applied in the genetic diversity analysis. Morphological identification of tsetse species is challenging and sometimes inaccurate. Therefore, on the samples that were positive for GpSGHV, we used PCR generated ITS1 amplicons [17] to assess the taxonomic status of the seven tsetse species (Table 1). In the current study, the ITS1 PCR products were of the expected sizes, which confirmed the status of G. pallidipes (920 bp), G. f. fuscipes (618 bp), G. brevipalpis (778 bp), G. p. palpalis (618 bp) and G. austeni (633 bp) (Additional file 1; Figure S1A). These sizes were consistent with ITS1 PCR product sizes of known tsetse species reared at the IPCL [17]. The G. m. morsitans and 
Table 1 Details of Glossina species sampled in different sites in Africa

\begin{tabular}{|c|c|c|c|c|c|c|c|}
\hline Country & Location & Species & Collection date & Latitude & Longitude & Total number & Prevalence (\%) \\
\hline \multicolumn{8}{|c|}{ Field collected samples } \\
\hline \multirow[t]{4}{*}{ Uganda } & Tororo & G. f. fuscipes & 1994 & $0^{\circ} 41^{\prime} 34.0^{\prime \prime} \mathrm{N}$ & $34^{\circ} 10^{\prime} 52.0^{\prime \prime} \mathrm{E}$ & 17 & $6(35.3 \%)$ \\
\hline & Buvuma Island & G. f. fuscipes* & 1994 & $0^{\circ} 14^{\prime} 36.7^{\prime \prime} \mathrm{N}$ & $33^{\circ} 16^{\prime} 53.9^{\prime \prime E}$ & 10 & $4(40.0 \%)$ \\
\hline & Kiyindi Island & G. f. fuscipes & 1994 & $0^{\circ} 19^{\prime} 20.4^{\prime \prime} \mathrm{N}$ & $32^{\circ} 59^{\prime} 34.2^{\prime \prime} \mathrm{E}$ & 8 & $2(25.0 \%)$ \\
\hline & Bagala Island & G. f. fuscipes & 1994 & $0^{\circ} 25^{\prime} 15.2^{\prime \prime S}$ & $32^{\circ} 14^{\prime} 38.1{ }^{\prime \prime E}$ & 18 & $5(27.8 \%)$ \\
\hline Ethiopia & Arba Minch & G. pallidipes* & 2006 & $6^{\circ} 07^{\prime} 01.2^{\prime \prime} \mathrm{N}$ & $37^{\circ} 01^{\prime} 60.0^{\prime \prime} \mathrm{E}$ & 431 & $297(68.9 \%)$ \\
\hline \multirow[t]{10}{*}{ Kenya } & Mwea & G. pallidipes* & 2007 & $0^{\circ} 53^{\prime} 15.9^{\prime \prime} \mathrm{N}$ & $37^{\circ} 37^{\prime} 59.7^{\prime \prime E}$ & 233 & $17(7.3 \%)$ \\
\hline & Mwea N. Park & G. pallidipes & 2008 & $0^{\circ} 49^{\prime} 23.2^{\prime \prime} \mathrm{S}$ & $37^{\circ} 37^{\prime} 02.3^{\prime \prime} \mathrm{E}$ & 21 & $1(4.8 \%)$ \\
\hline & Katotoi & G. pallidipes & 2007 & $0^{\circ} 42^{\prime} 42.7^{\prime \prime} \mathrm{N}$ & $34^{\circ} 18^{\prime} 57.11^{\prime \prime} \mathrm{E}$ & 226 & $0(0.0 \%)$ \\
\hline & Meru N.Park & G. pallidipes & 2008 & $0^{\circ} 05^{\prime} 18.2^{\prime \prime} \mathrm{N}$ & $38^{\circ} 11^{\prime} 23.8^{\prime \prime E}$ & 95 & $1(1.1 \%)$ \\
\hline & Kiria & G. pallidipes & 2008 & $0^{\circ} 31$ '09.8"S & $36^{\circ} 37^{\prime} 27.3^{\prime \prime} \mathrm{E}$ & 20 & $0(0.0 \%)$ \\
\hline & Koibos Soi & G. pallidipes* & 2008 & $0^{\circ} 09^{\prime} 57.9^{\prime \prime} \mathrm{N}$ & $36^{\circ} 06^{\prime} 20.6^{\prime \prime} \mathrm{E}$ & 94 & 19 (20.2\%) \\
\hline & Mogotio-Emsos & G. pallidipes* & 2008 & $0^{\circ} 01 ' 00.4^{\prime \prime S}$ & $35^{\circ} 57^{\prime} 32.7^{\prime \prime E}$ & 72 & $14(19.4 \%)$ \\
\hline & Ruma N. Park & G. pallidipes* & 2007 & $0^{\circ} 38^{\prime} 44.8^{\prime \prime S}$ & $34^{\circ} 16^{\prime} 31.8^{\prime \prime E}$ & 176 & $3(1.7 \%)$ \\
\hline & Obekai & G. f. fuscipes & 2007 & $0^{\circ} 30^{\prime} 52.5^{\prime \prime} \mathrm{N}$ & $34^{\circ} 12^{\prime} 17.6^{\prime \prime} \mathrm{E}$ & 38 & $0(0.0 \%)$ \\
\hline & Ikapolok & G. f. fuscipes & 2007 & $0^{\circ} 37^{\prime} 44.9^{\prime \prime} \mathrm{N}$ & $34^{\circ} 18^{\prime} 38.0^{\prime \prime} \mathrm{E}$ & 52 & $0(0.0 \%)$ \\
\hline \multirow[t]{6}{*}{ Tanzania } & Kwekivu & G. pallidipes* & 2005 & $5^{\circ} 46^{\prime} 30.5^{\prime \prime S}$ & $37^{\circ} 23^{\prime} 55.4^{\prime \prime} \mathrm{E}$ & 50 & 44 (88.0\%) \\
\hline & & G. m. morsitans* & 2005 & & & 50 & 29 (58.0\%) \\
\hline & Kwamume & G. pallidipes* & 2005 & $5^{\circ} 41^{\prime} 51.9^{\prime \prime} \mathrm{S}$ & $37^{\circ} 52^{\prime} 01.3^{\prime \prime E}$ & 33 & 1 (3.0\%) \\
\hline & & G. m. morsitans & 2005 & & & 50 & $0(0.0 \%)$ \\
\hline & Ikorongo GR & G. swynnertoni* & 2015 & $1^{\circ} 54^{\prime} 58.8^{\prime \prime S}$ & $34^{\circ} 43^{\prime} 49.8^{\prime \prime} \mathrm{E}$ & 48 & 23 (47.9\%) \\
\hline & Jozani, Zanzibar & G. austeni & 1994 & $6^{\circ} 14^{\prime} 28.4^{\prime \prime} S$ & $39^{\circ} 24^{\prime} 50.3^{\prime \prime} \mathrm{E}$ & 29 & $6(20.7 \%)$ \\
\hline \multirow[t]{2}{*}{ Zambia } & Mfuwe & G. pallidipes* & 2007 & $13^{\circ} 04^{\prime} 41.2^{\prime \prime} \mathrm{S}$ & $31^{\circ} 47^{\prime} 26.5^{\prime \prime E}$ & 201 & 49 (24.1\%) \\
\hline & & G. m. morsitans* & 2007 & & & 116 & $9(7.8 \%)$ \\
\hline \multirow[t]{10}{*}{ Zimbabwe } & Mashumbi & G. pallidipes* & 2006 & $15^{\circ} 56^{\prime} 13.8^{\prime \prime} \mathrm{S}$ & $29^{\circ} 27^{\prime} 25.7^{\prime \prime} \mathrm{E}$ & 50 & $1(2.0 \%)$ \\
\hline & & G.m. morsitans & 2006 & & & 8 & $0(0.0 \%)$ \\
\hline & Gokwe & G. pallidipes* & 2006 & $17^{\circ} 36^{\prime} 14.5^{\prime \prime S}$ & $28^{\circ} 27^{\prime} 41.1 \mathrm{IE}$ & 150 & $10(6.7 \%)$ \\
\hline & & G.m. morsitans & 2006 & & & 92 & $23(25.0 \%)$ \\
\hline & Ruckomechi & G. pallidipes* & 2006 & $15^{\circ} 50^{\prime} 55.0^{\prime \prime} \mathrm{S}$ & $29^{\circ} 07^{\prime} 30.0^{\prime \prime} \mathrm{E}$ & 97 & 30 (30.9\%) \\
\hline & & G. m. morsitans* & 2006 & & & 103 & 21 (20.4\%) \\
\hline & Makuti & G. pallidipes & 2006 & $16^{\circ} 17^{\prime} 59.0^{\prime \prime S}$ & $29^{\circ} 17^{\prime} 59.9^{\prime \prime} \mathrm{E}$ & 96 & $0(0.0 \%)$ \\
\hline & & G. m. morsitans* & 2006 & & & 99 & $9(9.1 \%)$ \\
\hline & Mukondore & G.m. morsitans & 1995 & $16^{\circ} 05^{\prime} 22.7^{\prime \prime S}$ & $29^{\circ} 14^{\prime} 36.0^{\prime \prime} \mathrm{E}$ & 36 & $18(50.0 \%)$ \\
\hline & Chiuyi & G. m. morsitans & 1995 & $16^{\circ} 6^{\prime} 31.6^{\prime \prime S}$ & $29^{\circ} 24^{\prime} 33.8^{\prime \prime} \mathrm{E}$ & 36 & $19(50.0 \%)$ \\
\hline DRC & Malanga & G. p. palpalis* & 1995 & $5^{\circ} 33^{\prime} 26.6^{\prime \prime S}$ & $14^{\circ} 21^{\prime} 00.1 \mathrm{IE}$ & 52 & $4(7.7 \%)$ \\
\hline \multirow[t]{2}{*}{ South Africa } & Zululand & G. brevipalpis* & 1995 & $28^{\circ} 01^{\prime} 07.2^{\prime \prime} \mathrm{S}$ & $32^{\circ} 12^{\prime} 52.6^{\prime \prime} \mathrm{E}$ & 33 & $5(15.2 \%)$ \\
\hline & & G. austeni* & 1999 & & & 53 & $14(26.4 \%)$ \\
\hline \multicolumn{8}{|c|}{ Laboratory colonised Glossina species } \\
\hline Uganda & Tororo (IPCL) & G. pallidipes* & 2010 & $0^{\circ} 41^{\prime} 34.0^{\prime \prime} \mathrm{N}$ & $34^{\circ} 10^{\prime} 52.0^{\prime \prime} \mathrm{E}$ & 48 & $48(100.0 \%)$ \\
\hline \multirow[t]{2}{*}{ Kenya } & BioRI-KALRO & G. pallidipes & 2008 & $1^{\circ} 13^{\prime} 28.0^{\prime \prime} \mathrm{S}$ & $36^{\circ} 38^{\prime} 10.2^{\prime \prime} \mathrm{E}$ & 99 & $1(1.0 \%)$ \\
\hline & & G. m. morsitans* & 2008 & & & 89 & 16 (17.9\%) \\
\hline Total & & & & & & 3229 & \\
\hline
\end{tabular}

Samples were collected from different geographical sites in eastern, southern and central African countries for the analysis of GpSGHV prevalence and genetic diversity. Only the samples marked by a star $\left(^{*}\right)$ were further analysed for GpSGHV genetic diversity 
G. swynnertoni with equal ITS1 sequence lengths (775 bp) were distinguished by the presence of the endosymbiont Wolbachia in G. m. morsitans, and its absence in G. swynnertoni (Additional file 1: Figure S1B). Wolbachia integration and prevalence in G. m. morsitans was evidenced by the lower (296 bp) and the upper (438 bp) bands on the agarose gel (Additional file 1: Figure S1B). The variations in the Wolbachia prevalence agreed with previous studies in field and laboratory tsetse populations [18].

The GpSGHV prevalence was highest in the G. pallidipes colonized at FAO/IAEA Insect Pest Control Laboratory (IPCL) that originated from Tororo, (Uganda; 100\%), followed by Kwekivu (Tanzania; 88\%), Arba-Minch (Ethiopia; 68.9\%), and Ruckomechi (Zimbabwe; 30.9\%) (Table 1). The virus was not detected in G. pallidipes populations from Kiria and Katotoi in Kenya. The prevalence of the virus in G. $m$. morsitans flies was highest in the field collected samples from Kwekivu (Tanzania; 58\%), Chiuyi and Mukondore (Zimbabwe; $52 \%$ and 50\%, respectively) compared to the laboratory colonised G. m. morsitans from BRI-KALRO (17.9\%). The virus prevalence varied widely amongst the Ugandan G. f. fuscipes specimens (40\%, 35.3\%, 27\% and 25\% in Buvuma, Tororo, Bagala Island and Kiyindi Island, respectively), whereas the virus was not detected in the Kenyan G. $f$. fuscipes specimens. The virus prevalence was likewise high (47.9\%) in the G. swynnertoni specimens from the Ikorongo Game Reserve in Tanzania, but lower in the populations of G. austeni (26.4\%) and G. brevipalpis, (15.2\%) from KwaZulu Natal, South Africa, and in specimens of G. $p$. palpalis from Malanga, Democratic Republic of the Congo (7.7\%) (Table 1). These results provide evidence that the GpSGHV is present in multiple tsetse species, to varying degrees under laboratory and field conditions.

\section{Geographical distribution of GpSGHV haplotypes}

The VNTR-2 sequences, which were successfully obtained from all individual GpSGHV positive samples in the seven tsetse species revealed 14 GpSGHV haplotypes (Fig. 1a). Sequence analysis using the alignments of the concatenated sequences of the 3 conserved genes and the two VNTRs revealed 15 GpSGHV haplotypes due to sequence differences found in SGHV009 of G. pallidipes samples from Mwea, Kenya (Fig. 1b). However, the relationship between the other 14 haplotypes did not change when the analysis was performed using either the VNTR-2 or concatenated sequences. SGHV009, SGHV010 and SGHV038 and the VNTR-1 of some of the samples could not be sequenced due to failure to amplify the region with the PCR conditions used in the current study. VNTR-2 was the only successfully sequenced region in all the representative samples. The distribution of the identified haplotypes over the Glossina species varied depending on the geographical locations (Table 2). Haplotype H1, which corresponded to the GpSGHV-Uga reference [19], was with the exception of G. swynnertoni, found in all examined Glossina species. This haplotype was found in tsetse populations sampled in 10 different locations in seven of the eight
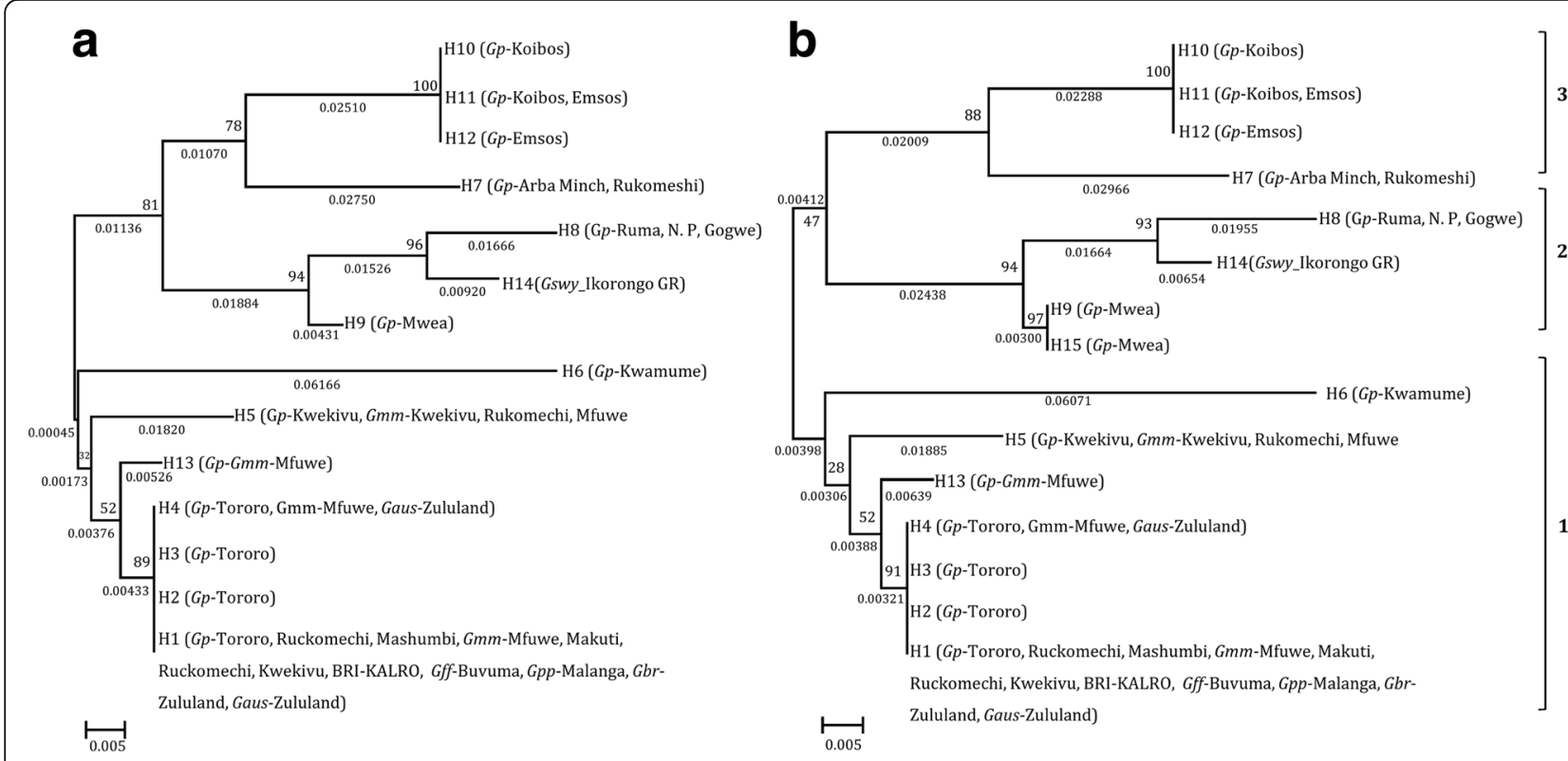

Fig. 1 GpSGHV haplotypes in Glossina species: Maximum Likelihood (ML) phylogenetic tree for the GpSGHV strains from different geographical locations in Africa using (a) VNTR-2 and (b) concatenated sequences of VNTR-1, VNTR-2, ORF009, ORF010 and ORF038. ML bootstrap values based on 1000 replicates are shown on the branches. Abbreviations: Gp (G. pallidipes), Gmm (G. m. morsitans), Gswy (G. swynnertoni), Gff (G. f. fuscipes), Gbr (G. brevipalpis), Gpp (G. p. palpalis), and Gaus (G. austeni) 
countries (except in Ethiopia) (see Table 2). Seven of the 15 GpSGHV haplotypes (H2, H3, H6, H9, H10, H12 and H15) were restricted to G. pallidipes specimens in specific locations. Haplotype H5 was detected in G. pallidipes and G. m. morsitans from Kwekivu, Tanzania, in G. m. morsitans from Ruckomechi, Zimbabwe and from Mfuwe, Zambia (Table 2). Haplotypes H7, H8 and H11 were each detected in G. pallidipes specimens from two distinct locations, while $\mathrm{H} 13$ was restricted to Zambian G. pallidipes and G. m. morsitans specimens. Haplotype H14 was restricted to the G. swynnertoni samples from the Ikorongo Game Reserve in Tanzania. Notably, in some cases, the same tsetse species (but not the same individual flies) from the same geographical locations harboured more than one haplotype. For example, G. pallidipes from Kenya, were infected with $\mathrm{H} 10$ and $\mathrm{H} 11$ (Koibos-Soi), and H11 and H12 (Emsos) (Fig. 2). Similar observations were made in the haplotypes infecting $G$. pallidipes from IPCL originated from Uganda $(\mathrm{H} 1, \mathrm{H} 2$, $\mathrm{H} 3$ and $\mathrm{H} 4)$.

\section{Single nucleotide polymorphisms (SNPs) and nonsynonymous mutations among GpSGHV haplotypes} After analysing the GpSGHV haplotype distribution amongst the Glossina species from the different geographical locations (Table 3), we determined synonymous and nonsynonymous single nucleotide polymorphisms (SNPs) in the amplified nucleotide sequences. The analysis revealed a high rate of SNPs, and a few deletions and insertions (Table 3). Haplotype H1, which is similar to the

Table 2 Descriptions of the 15 GpSGHV haplotypes (abbreviated by 'H') identified in Glossina species from different geographical locations

\begin{tabular}{|c|c|c|c|c|c|c|c|c|c|}
\hline \multirow[t]{2}{*}{ Country } & \multirow[t]{2}{*}{ Location } & \multirow[t]{2}{*}{ Species } & \multirow[t]{2}{*}{ Tested flies } & \multicolumn{5}{|c|}{$\begin{array}{l}\text { Haplotype } \\
\text { (No of tested samples occurring in the haplotype) }\end{array}$} & \multirow{2}{*}{$\begin{array}{l}\text { Total no. of haplotypes within } \\
\text { the Glossina species (haplotype } \\
\text { name) }\end{array}$} \\
\hline & & & & $\begin{array}{l}\text { VNTR- } \\
1\end{array}$ & VNTR-2 & SGHV009 & SGHV010 & SGHV038 & \\
\hline \multirow[t]{2}{*}{ Uganda } & Tororo & G. pallidipes & 8 & $\mathrm{H} 1(8)$ & $\begin{array}{l}\mathrm{H} 1(5), \mathrm{H} 2(1) \\
\mathrm{H} 3(1), \mathrm{H} 4(1)\end{array}$ & $\mathrm{H} 1(8)$ & $\mathrm{H} 1(8)$ & $\mathrm{H} 1(8)$ & $4(\mathrm{H} 1, \mathrm{H} 2, \mathrm{H} 3, \mathrm{H} 4)$ \\
\hline & Buvuma Island & G. f. fuscipes & 9 & $\mathrm{H} 1(6)$ & $\mathrm{H} 1(9)$ & - & - & - & $1(\mathrm{H} 1)$ \\
\hline Ethiopia & Arba Minch & G. pallidipes & 8 & $\mathrm{H} 7(8)$ & $\mathrm{H} 7(8)$ & $\mathrm{H} 7(8)$ & $\mathrm{H} 7(8)$ & $\mathrm{H} 7(8)$ & $1(\mathrm{H} 7)$ \\
\hline \multirow[t]{5}{*}{ Kenya } & Mwea & G. pallidipes & 5 & $\mathrm{H} 9(1)$ & $\mathrm{H} 9(5)$ & $\begin{array}{l}\mathrm{H} 9(2) \\
\mathrm{H} 15(1)\end{array}$ & $\mathrm{H} 9(3)$ & $\mathrm{H} 9(3)$ & $2(\mathrm{H} 9, \mathrm{H} 15)$ \\
\hline & Koibos Soi & G. pallidipes & 8 & - & $\begin{array}{l}\mathrm{H} 10(7) \\
\mathrm{H} 11(1)\end{array}$ & $\mathrm{H} 11(4)$ & $\mathrm{H} 11(4)$ & $\mathrm{H} 11(4)$ & $2(\mathrm{H} 10, \mathrm{H} 11)$ \\
\hline & Emsos & G. pallidipes & 8 & - & $\begin{array}{l}\mathrm{H} 11(7) \\
\mathrm{H} 12(1)\end{array}$ & $\mathrm{H} 11(2)$ & $\mathrm{H} 11(2)$ & $\mathrm{H} 11(2)$ & $2(\mathrm{H} 11, \mathrm{H} 12)$ \\
\hline & BioRI-KALRO & G. m. morsitans & 16 & $\mathrm{H} 1(12)$ & $\mathrm{H} 1(16)$ & - & - & - & $1(\mathrm{H} 1)$ \\
\hline & Ruma N Park & G. pallidipes & 1 & - & $\mathrm{H} 8(1)$ & - & $\mathrm{H} 8(1)$ & $\mathrm{H} 8(1)$ & $1(\mathrm{H} 8)$ \\
\hline \multirow[t]{4}{*}{ Tanzania } & Kwamume & G. pallidipes & 1 & $\mathrm{H} 6(1)$ & H6(1) & - & - & - & $1(\mathrm{H} 6)$ \\
\hline & Kwekivu & G. pallidipes & 8 & $\mathrm{H} 5(4)$ & $\mathrm{H} 5(8)$ & $\mathrm{H} 5(6)$ & $\mathrm{H} 5(6)$ & $\mathrm{H} 5(6)$ & $1(\mathrm{H} 5)$ \\
\hline & & G. m. morsitans & 17 & $\mathrm{H} 1(1)$ & $\mathrm{H1}(6), \mathrm{H} 5(11)$ & $\mathrm{H} 1(4)$ & $\mathrm{H} 1(4)$ & $\mathrm{H} 1(4)$ & $2(\mathrm{H1}, \mathrm{H} 5)$ \\
\hline & Ikorongo GR & G. swynnertoni & 3 & - & $\mathrm{H} 14(3)$ & $\mathrm{H} 14(3)$ & $\mathrm{H} 14(3)$ & $\mathrm{H} 14(3)$ & $1(\mathrm{H} 14)$ \\
\hline \multirow[t]{2}{*}{ Zambia } & Mfuwe & G. pallidipes & 4 & - & $\mathrm{H} 13(4)$ & $\mathrm{H} 1(4)$ & $\mathrm{H} 1(4)$ & $\mathrm{H} 1(4)$ & $2(\mathrm{H} 1, \mathrm{H} 13)$ \\
\hline & & G. m. morsitans & 9 & $\mathrm{H} 1(7)$ & $\begin{array}{l}\mathrm{H} 13(6), \mathrm{H} 1(1) \\
\mathrm{H} 4(1), \mathrm{H} 5(1)\end{array}$ & - & - & - & $4(\mathrm{H} 1, \mathrm{H} 4, \mathrm{H} 5, \mathrm{H} 13)$ \\
\hline \multirow[t]{5}{*}{ Zimbabwe } & Mashumbi & G. pallidipes & 1 & - & $\mathrm{H} 1(1)$ & - & - & - & $1(\mathrm{H} 1)$ \\
\hline & Gokwe & G. pallidipes & 1 & - & $\mathrm{H} 8(1)$ & - & - & - & $1(\mathrm{H} 8)$ \\
\hline & Ruckomechi & G. pallidipes & 8 & $\mathrm{H} 1(3)$ & $\mathrm{H} 1(7), \mathrm{H} 7(1)$ & $\mathrm{H} 1(3)$ & $\mathrm{H} 1(3)$ & $\mathrm{H} 1(3)$ & $2(\mathrm{H} 1, \mathrm{H} 7)$ \\
\hline & & G. m. morsitans & 14 & $\mathrm{H} 1(12)$ & $\mathrm{H} 1(13), \mathrm{H} 5(1)$ & $\mathrm{H} 1(3)$ & $\mathrm{H} 1(3)$ & $\mathrm{H} 1(3)$ & $2(\mathrm{H} 1, \mathrm{H} 5)$ \\
\hline & Makuti & G. m. morsitans & 8 & - & $\mathrm{H} 1(8)$ & $\mathrm{H} 1(1)$ & $\mathrm{H} 1(1)$ & $\mathrm{H} 1(1)$ & $1(\mathrm{H} 1)$ \\
\hline DRC & Malanga & G.p. palpalis & 4 & $\mathrm{H} 1(3)$ & $\mathrm{H} 1(4)$ & - & - & - & $1(\mathrm{H} 1)$ \\
\hline \multirow[t]{2}{*}{ South Africa } & Zululand & G. brevipalpis & 5 & $\mathrm{H} 1(4)$ & $\mathrm{H} 1(5)$ & - & - & - & $1(\mathrm{H} 1)$ \\
\hline & & G. austeni & 6 & $\mathrm{H} 1(2)$ & $\mathrm{H} 1(5), \mathrm{H} 4(1)$ & - & - & - & $2(\mathrm{H} 1, \mathrm{H} 4)$ \\
\hline
\end{tabular}




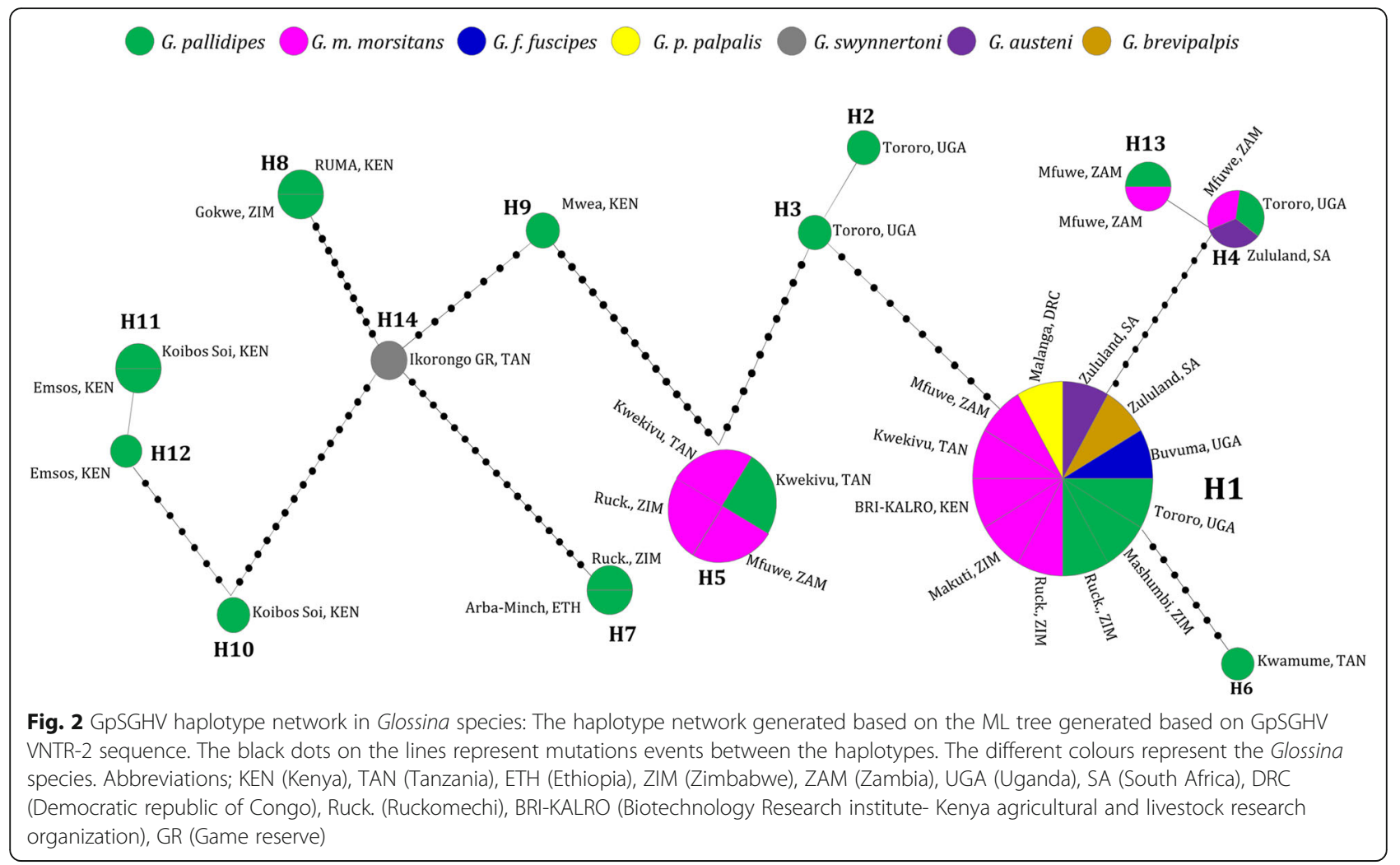

reference GpSGHV-Uga, remained without mutations within the haplotype. Most of the deletions and insertions were found in the VNTRs, with the VNTR-2 presenting most of the inter- and intra-haplotype variations. The VNTRs mutations observed were mostly patterns in repeat polymorphisms, i.e. additions or deletions of repeat units, rather than single nucleotide mutations (Additional file 2: Figure S2B). VNTR-2 of H7, which infected the Ethiopian (Arba Minch) and Zimbabwean (Ruckomechi) G. pallidipes populations, harboured the most intra-haplotype variation (i.e. 24 SNPs, and 126 bp and $20 \mathrm{bp}$ insertions and deletions, respectively) (Table 3). Compared to the GpSGHV-Uga reference sequence, most of the nonsynonymous mutations of 19 of 178,12 of 475 and 10 of 489 amino acids in SGHV009, SGHV010 and SGHV038, respectively, were found in the $\mathrm{H} 7$ infecting the Ethiopian (Arba Minch) and Zimbabwean (Ruckomechi) G. pallidipes populations (Table 3). Further, H10, H11 and H12 infecting G. pallidipes populations from Kenya (Koibos-Soi and Emsos) also presented high mutational variations within the haplotype, with five of 178, 12 of 475 and nine of 489 amino acids of nonsynonymous mutations in SGHV009, SGHV010 and SGHV038, respectively. The greatest number of nonsynonymous mutations was found in the haplotypes infecting G. pallidipes populations, followed by those infecting the G. m. morsitans populations (see Table 3).

\section{Phylogenetic analysis of GpSGHV haplotypes}

Analysis of the phylogenetic relationships of the various GpSGHV haplotypes revealed three distinct clades consisting of haplotypes from different locations (Fig. 1). The largest clade (clade 1) consisted of haplotypes H1, $\mathrm{H} 2, \mathrm{H} 3, \mathrm{H} 4, \mathrm{H} 5, \mathrm{H} 6$ and $\mathrm{H} 13$ infecting six out of seven Glossina species derived from most of the geographical locations. Clade 2 consisted of H8, H9, H14 and H15, which infected G. pallidipes from Mwea, Ruma (Kenya), Gokwe (Zimbabwe) and G. swynnertoni from the Ikorongo Game reserve (Tanzania). The third clade included H7, H10, H11 and H12 infecting G. pallidipes samples from Koibos-Soi, Emsos (Kenya), Arba Minch (Ethiopia) and Ruckomechi (Zimbabwe) (Fig. 1). The clustering of the Kenyan haplotypes (H10, H11 and H12, infecting G. pallidipes) in clade 3, which was supported by $100 \%$ bootstrap values, appeared to be closely related to the Ethiopian H7. H7 is presumably the GpSGHV-Eth strain, whose genome has been fully sequenced and which might be more pathogenic than the reference GpSGHV-Uga strain (H1) [11].

\section{Potential ancestry of GpSGHV haplotypes}

To gain insights into the evolutionary history of GpSGHV, which can be seen as a series of mutation events leading to the various haplotypes, we analysed the genealogies (or gene trees) [20] using both VNTR-2 
Table 3 Analysis of PCR product lengths in nucleotides, single nucleotide polymorphisms (SNPs), insertion and deletions detected in the GpSGHV haplotypes in the Glossina species

\begin{tabular}{|c|c|c|c|c|c|c|c|c|}
\hline \multirow[t]{2}{*}{ Haplotype } & \multirow[t]{2}{*}{ Species } & \multirow[t]{2}{*}{ Location } & \multicolumn{5}{|c|}{ PCR Length: (SNPs, insertion, deletion) (bp) } & \multirow{2}{*}{$\begin{array}{l}\text { No. of nonsynonymous } \\
\text { mutations (aa) } \\
\text { (SGHV009, SGHV010, } \\
\text { SGHV038) }\end{array}$} \\
\hline & & & VNTR-1 & VNTR-2 & SGHV009 & SGHV010 & SGHV038 & \\
\hline GpSGHV-Uga & Reference & NCBI & 370 & 437 & 535 & 1425 & 1461 & Reference \\
\hline \multirow[t]{12}{*}{$\mathrm{H} 1$} & G. pallidipes & Tororo & 370: $(0,0,0)$ & 437: $(0,0,0)$ & 535: $(0,0,0)$ & 1425: $(0,0,0)$ & 1461: $(0,0,0)$ & $(0,0,0)$ \\
\hline & G. m. morsitans & Ruckomechi & & & & & & \\
\hline & G. m. morsitans & Mfuwe & & & & & & \\
\hline & G. m. morsitans & Makuti & & & & & & \\
\hline & G. pallidipes & Ruckomechi & & & & & & \\
\hline & G. pallidipes & Mashumbi & & & & & & \\
\hline & G. m. morsitans & BioRI-KALRO & & & & & & \\
\hline & G. m. morsitans & Kwekivu & & & & & & \\
\hline & G. f. fuscipes & Buvuma Island & & & & & & \\
\hline & G.p. palpalis & Malanga & & & & & & \\
\hline & G. brevipalpis & Zululand & & & & & & \\
\hline & G. austeni & Zululand & & & & & & \\
\hline $\mathrm{H} 2$ & G. pallidipes & Tororo & 370: $(0,0,0)$ & 500: $(2,63,0)$ & 535: $(0,0,0)$ & 1425: $(0,0,0)$ & 1461: $(0,0,0)$ & $(0,0,0)$ \\
\hline H3 & G. pallidipes & Tororo & 370: $(0,0,0)$ & 500: $(0,63,0)$ & 535: $(0,0,0)$ & 1425: $(0,0,0)$ & 1461: $(0,0,0)$ & $(0,0,0)$ \\
\hline \multirow[t]{3}{*}{$\mathrm{H} 4$} & G. pallidipes & Tororo & 370: $(0,0,0)$ & 374: $(0,0,63)$ & 535: $(0,0,0)$ & 1425: $(0,0,0)$ & 1461: $(0,0,0)$ & $(0.0,0)$ \\
\hline & G. m. morsitans & Mfuwe & & & & & & \\
\hline & G. austeni & Zululand & & & & & & \\
\hline \multirow[t]{4}{*}{ H5 } & G. pallidipes & Kwekivu & 416: $(12,66,20)$ & 542: $(15,105,0)$ & 538: $(1,3,0)$ & 1425: $(4,0,0)$ & 1467: $(12,6,0)$ & $(1,1,4)$ \\
\hline & G. m. morsitans & Kwekivu & & & & & & \\
\hline & G. m. morsitans & Ruckomechi & & & & & & \\
\hline & G. m. morsitans & Mfuwe & & & & & & \\
\hline H6 & G. pallidipes & Kwamume & 415: $(13,65,20)$ & 458: $(14,21,1)$ & $?$ & $?$ & $?$ & $?$ \\
\hline \multirow[t]{2}{*}{ H7 } & G. pallidipes & Arba Minch & 272: $(8,1,99)$ & 542: $(24,126,20)$ & 571: $(14,36,0)$ & 1425: $(16,0,0)$ & 1458: $(26,0,3)$ & $(19,12,10)$ \\
\hline & G. pallidipes & Ruckomechi & & & & & & \\
\hline \multirow[t]{2}{*}{$\mathrm{H} 8$} & G. pallidipes & Gokwe & $?$ & 483: $(47,46,0)$ & $?$ & 1425: $(14,0,0)$ & 1460: $(14,0,0)$ & $(?, 9,2)$ \\
\hline & G. pallidipes & Ruma N. Park & & & & & & \\
\hline H9 & G. pallidipes & Mwea & 431: $(11,61,0)$ & 521: $(30,84,0)$ & 523: $(7,0,12)$ & 1425: $(11,0,0)$ & 1460: $(20,0,1)$ & $(3,7,5)$ \\
\hline $\mathrm{H} 10$ & G. pallidipes & Koibos Soi & $?$ & 458: $(40,21,0)$ & 529: $(6,3,9)$ & 1425: $(15,0,0)$ & 1461: $(21,0,0)$ & $(5,12,9)$ \\
\hline \multirow[t]{2}{*}{$\mathrm{H} 11$} & G. pallidipes & Koibos Soi & $?$ & 416: $(36,0,21)$ & 529: $(6,3,9)$ & 1425: $(15,0,0)$ & 1461: $(21,0,0)$ & $(5,12,9)$ \\
\hline & G. pallidipes & Emsos & & & & & & \\
\hline $\mathrm{H} 12$ & G. pallidipes & Emsos & $?$ & 416: $(35,0,63)$ & 529: $(6,3,9)$ & 1425: $(15,0,0)$ & 1461: $(21,0,0)$ & $(5,12,9)$ \\
\hline \multirow[t]{2}{*}{$\mathrm{H} 13$} & G. pallidipes & Mfuwe & $?$ & 374: $(3,0,63)$ & 535: $(0,0,0)$ & 1425: $(0,0,0)$ & 1461: $(0,0,0)$ & $(0,0,0)$ \\
\hline & G. m. morsitans & Mfuwe & & & & & & \\
\hline H14 & G. swynnertoni & Ikorongo GR & $?$ & 503: $(36,67,0)$ & 532: $(3,0,3)$ & 1425: $(14,0,0)$ & 1467: $(16,6,0)$ & $(1,9,6)$ \\
\hline H15 & G. pallidipes & Mwea & 431: $(11,61,0)$ & 521: $(30,84,0)$ & 532: $(3,3,6)$ & 1425: $(11,0,0)$ & 1460: $(20,0,1)$ & $(2,7,5)$ \\
\hline
\end{tabular}

The polymorphisms were based on the partial sequences of GpSGHV ORFs SGHV009, SGHV010, SGHV038, VNTR-1 and VNTR-2. The 3 numbers in brackets for each haplotype in column four to column eight refer to the number of SNPs, insertions and deletions respectively, relative to the GpSGHV-Uga reference sequences. The samples marked with a question mark (?) were not successfully sequenced. The nonsynonymous mutations of SGHV009, SGHV010, SGHV038 found in each sample are also shown in the last column 
alone (Fig. 2) and the concatenated gene sequences of the above-mentioned three genes and the two VNTRs (Additional file 3: Figure S3). The haplotype genealogies did not differ when analysed using either the VNTR-2 or the concatenated sequences. In order to be able to include also H15, which is similar to H9 in VTNR-2 sequence and only differ at SGHV009 sequence, the concatenated sequences were used for the analysis. The topology of the star-like genealogies revealed three potential ancestral origins of the various GpSGHV haplotypes (Fig. 2), which were largely in agreement with the clustering observed in the phylogeny (Figs. 1 and 2). Due to its large host range and wide geographical representations, we presumed $\mathrm{H} 1$ to be the ancestral origin of all the 15 haplotypes (i.e. shared parental DNA sequences). This would be in line with the wide distribution of $\mathrm{H} 1$ described above (in six of the seven Glossina species, originating from 10 of geographical locations (Fig. 2). Further, H6 (infecting G. pallidipes only), H4 (infecting G. pallidipes, G. m. morsitans and G. austeni), and H13 (infecting G. pallidipes and G. m. morsitans) potentially trace back to $\mathrm{H} 1$ by eight and 11 mutation events, respectively. H5 was the second potential ancestral haplotype origin. Notably, based on the analysed genes in this study, $\mathrm{H} 2$ and $\mathrm{H} 3$ (infecting the IPCL G. pallidipes populations) presumably coalesced from $\mathrm{H} 1$ and $\mathrm{H} 5$ by 11 and 10 mutation events, respectively (Fig. 2; see also Table 3). On the other hand, H14, which infects the G. swynnertoni from the Ikorongo Game reserve in Tanzania, can be interpreted to be the ancestral origin of $\mathrm{H} 7, \mathrm{H} 8, \mathrm{H} 9$, and H10. Additionally, $\mathrm{H} 9$ and H15 (Additional file 3: Figure S3) potentially coalesced from H5 and H14 by $7-8$ and 15-16 mutation events, respectively. Finally, H10, H11 and $\mathrm{H} 12$ from Kenya showed the highest divergence from $\mathrm{H} 1$, which as mentioned above, corresponded to the reference GpSGHV-Uga.

\section{Discussion}

This study provides the first evidence that all seven Glossina species examined harboured GpSGHV. The ability of GpSGHV to infect multiple Glossina species is important because the virus could hamper future SIT efforts as part of AW-IPM programmes against specific Glossina species in various sub-Saharan African countries. This finding is especially relevant for tsetse mass production facilities where multiple tsetse species are reared and often receive their blood meals using the same membranes in successive feeding cycles [21]. This feeding regime increases risks of virus transmission within and between the species. This cross-species virus transmission could result in viral amplifications and SGH outbreaks in laboratory colonies or mass rearing facilities (due to horizontal transmission of infectious virus particles via saliva during the in vitro membrane feeding [12]). Additionally, the cross-species virus transmission, could result in the generation within the original and new hosts of virus variants capable of efficient spreading amongst multiple host species [22].

The finding that GpSGHV prevalence was highest in G. pallidipes irrespective of the geographical locations (e.g. $100 \%$ in IPLC colony and $88 \%$ in Tanzania field samples) implies that the virus is present at high frequency in this species. This finding supports the view that this virus most probably has a recent relationship with G. pallidipes compared to other tsetse species analysed in this study, perhaps due to virus-host interactions that influence genetic drift and selection as reported for arbovirus infection in different mosquito species [16]. Next to G. pallidipes, the virus prevalence was high amongst populations of $G$. $m$. morsitans (e.g. 58\% in Tanzania and 20\% in Zimbabwe), and G. f. fuscipes (25-40\% in Uganda). It should be noted that SGH symptoms were first reported in the 1930's amongst G. pallidipes populations in the Umfolozi Game Reserve, KwaZulu Natal, South Africa [23], and later in the early 1970's the causative virus was observed in G. morsitans and G. f. fuscipes in Tanzania and Uganda, respectively $[24,25]$ Later, these virus particles were associated with SGH in G. pallidipes [26]. Decades later (in 1993), the virus was reported in G. brevipalpis populations in Kenya [27]. Overall, based on the chronological history since the initial discovery of SGH in Glossina [26], unlike others tsetse species, G. pallidipes is evidently the most common Glossina species to which GpSGHV has not yet evolutionarily adapted to [12]. It is yet to be determined why the virus is more pathogenic to G. pallidipes as compared with other Glossina species. It is obvious that a well-established evolutionary relationship between the virus and the host will result in a stable status, where the virus can be present in the host without affecting the host's general fitness or causing disease symptoms. What is known is that pathogens, including viruses, can specifically modulate their host-environment infections to favour their transmission [28].

The largest number of nonsynonymous mutations (in all the three genes) was found within the GpSGHV haplotypes infecting G. pallidipes populations from Ethiopia, Zimbabwe (H7), and Kenya (H10, H11 and H12). The nonsynonymous mutations provide a preview of the evolutionary path that can shape the genetic structure of viral haplotypes [29]. Of the two GpSGHV strains whose genomes have been fully sequenced, the Ethiopian strain (GpSGHV-Eth) had a higher (> 85\%) SGH prevalence in G. pallidipes originating from Ethiopia, than the Ugandan strain (GpSGHV-Uga) infecting $G$. pallidipes from Uganda (10\% SGH prevalence), despite the two colonies being maintained in the same insectary conditions in IPCL $[11,21,30]$. Whereas higher SGH incidences may not 
necessarily reflect higher pathogenicity, there are indications that this may be the case. It could be as well that the G. pallidipes flies from Ethiopia are less tolerant to the virus infection compared to the long domesticated G. pallidipes colony in IPCL [21]. In the current study, VNTR-2 revealed the highest rate of deletions and insertions of repeat units. VNTRs are amongst the most discriminating of the genotyping methods, and have been used in pedigree analysis of disease-causing pathogens due to their roles in rapid genome evolution and adaptations [31]. Although VNTRs usually generate neutral genetic variations [32], some VNTRs can alter critical biological functions. For instance, if localized near or within gene promoter regions, VNTRs may affect transcription of downstream genes by affecting the number of transcription factor binding sites, or inducing changes in spacing between critical promoter elements [33]. In addition, it has been reported that polymorphism in VNTR loci contributes to genome evolution [31]. In this study, the sequence analysis using either the VNTR-2 or the concatenate sequences of the three genes and two VNTRs revealed the same haplotypes. This indicates that VNTR-2 can be a suitable tool/ microsatellite to discriminate GpSGHV haplotypes. Of the three genes used in this study, SGHV010 and SGHV038, which code for putative desmoplakin-like protein and maltodextrin glycosyltransferase, respectively, are both virion tegument proteins [11, 34]. For some DNA viruses (e.g. herpesviruses), tegument proteins have been described that are essential for virus replication [35]. The third gene (SGHV009) is known to be homologues to viral regulatory proteins. Although the mutations in the three ORFs and the two VNTRs represent a small subset of the GpSGHV genome to make robust conclusions, we hypothesize that these mutations might affect the pathogenesis of GpSGHV-Eth as compared to the GpSGHV-Uga. It would be interesting to sequence the genomes of the GpSGHV strains circulating amongst the Zimbabwean and Kenyan G. pallidipes populations. This will help determine their genetic differences, compared to already sequenced GpSGHV strains. The nonsynonymous mutations found in these haplotypes need further investigations to elucidate their impacts on the virus pathobiology.

The central genealogy hubs (based on the haplotype network) occupied by haplotypes $\mathrm{H} 1$ (infecting six of the seven analysed Glossina species), H5 (infecting three Glossina species), and H14 (infecting only G. swynnertoni) provided insight into the potential ancestral origins and evolution of GpSGHV in Glossina. In addition, haplotype $\mathrm{H} 1$ is presumed to be the best potential ancestor of the virus among the three haplotypes due to its wide host-range and geographical representation. Hence, it was difficult and beyond the scope of this paper to trace the origin and evolution of the virus through the species host or the geographical locations. However, an accurate assessment of the origin and evolution of large dsDNA viruses needs to be based on whole genomes, including primary genomic sequence comparisons, genome organizations and gene content [36]. We have recently shown that the two GpSGHV strains (GpSGHV-Uga and GpSGHV-Eth), although similar in nucleotide sequence $(98.1 \%)$, differ in their genomes in terms of the numbers of ORFs (with insertions and deletions of entire ORFs), and SNPs within the genes [11]. We selected the three genes and the two VNTRs for our analyses because they exhibited the most significant differences between the two virus strains. Our hypothesis that $\mathrm{H} 1$ and $\mathrm{H} 5$ are potentially of ancestral origin is supported by previous findings by Kariithi et al. [15], who found the same haplotypes to occupy similar positions in the genealogical network. However, $\mathrm{H} 5$ from the previous study was found in G. pallidipes from Kenya, while in the current study $\mathrm{H} 5$ infected both G. m. morsitans and G. pallidipes from Tanzania, and G. m. morsitans from Zimbabwe and Zambia. In the current study, we have identified H14 (infecting G. swynnertoni) as an additional possible ancestral GpSGHV origin. Further studies are necessary to characterize the haplotypes found in Kenya, which we found to be phylogenetically related to the GpSGHV-Eth, as well as to H14. Several authors from Kenya reported the occurrence of SGH symptoms in wild-caught Glossina species [See the summary in Table 1 from Kariithi et al.,] [12]. Since the occurrence of SGH symptoms is an exception [37], especially in wild tsetse populations, one could conclude that the GpSGHV strains circulating amongst the various tsetse populations in Kenya could be as pathogenic as the GpSGHV-Eth. Although we detected multiple GpSGHV haplotypes infecting the same tsetse species from the same geographical location, the occurrence of multiple GpSGHV haplotypes in single individuals was not tested. However, this phenomenon in the Glossina-GpSGHV system cannot be ruled out since multiple virus haplotypes in the same individual has been reported in other systems such as Drosophila-Drosophila C virus system [38]. Infection by multiple genotypes of nucleopolyhedrovirus has also been reported in Spodoptera frugiperda which contributed to the diversity of the virus [39].

These findings suggest that compared to other tsetse species included in this study, G. pallidipes might be the most recent host for GpSGHV. The large number of haplotypes observed in G. pallidipes suggests that the virus is still in the process of adapting to the host, explaining also why SGH symptoms were first observed in this species. This indicates that the original GpSGHV host species could be any other tsetse species that has yet to present overt SGH symptoms, or is even infected at levels that are too low to be detected by conventional PCR. We hypothesize that the virus might on rare 
occasions be transmitted horizontally between individuals and species when tsetse flies acquire a blood meal on the same animal in the field. In this scenario, infectious GpSGHV particles can pass from infected to uninfected flies via salivary secretions as up to $10^{6}$ viral copies are secreted by an infected symptomatic fly in a 10-15 min blood meal feeding event during membrane feeding in the laboratory [21, 30, 40]. These secreted virus particles can be infectious as evidenced by the reduction in virus copy numbers in flies fed with new blood at every feed, compared to flies fed under the normal feeding regime of feeding several sets of cages on the same tray of blood. [21, 30, 40]. In the field, tsetse flies aggregate on specific parts of the host to feed [41, $42]$ and produce pharmacologically active saliva components that are deposited by the flies at the feeding site to interfere with host responses such as vasoconstriction and thrombocyte aggregation. This helps create a blood pool at the bite site and maintain blood fluidity as well as reducing the blood diffusion rate [43]. This may reduce the dilution by the host animal at the bite site of any infectious viral particles released via the saliva of infected flies and hence increase the chances of horizontal virus transfer to the flies feeding in the bite site proximity. This hypothesis has been discussed previously [6], but needs experimental validation. Virus transmission through a shared food source has been demonstrated in the closest relative of GpSGHV, the MdSGHV that infects houseflies, whereby healthy flies became infected after they were fed on food contaminated by infected flies $[44,45]$. Similar modes of virus transmission have been reported in other insect viruses such as Israeli acute paralysis virus (IAPV) in bumblebees [46].

\section{Conclusions}

We have demonstrated that the GpSGHV diversity is higher in G. pallidipes compared to other Glossina species. However, the high virus diversity in G. pallidipes from the current study differed with the results obtained in the previous study by Kariithi et al., [12], which was based on conserved virus genes $(p 74, p i f-1$, pif-2, pif-3, and dnapol). In addition, our results appear to support the concept that GpSGHV has over evolutionary times reached a stable but dynamic equilibrium with Glossina species other than $G$. pallidipes. In G. pallidipes the virus seems to be undergoing co-adaptation, thus accounting for the higher prevalence and diversity. This concept is also supported by the fact that it is only in G. pallidipes, that under certain laboratory settings, support symptomatic SGHV infections. In the natural tsetse populations, SGH symptoms are rarely observed. Taken together, these two studies present VNTR-2 as a potential candidate to distinguish virus haplotypes since it was successfully sequenced in all the analysed individuals. This is as opposed to the use of the concatenated sequences that had missing sequences of VNTR-1, SGHV009, SGHV010 and SGHV038 in some individuals due to unsuccessful attempts to amplify these candidate genes.

The finding that GpSGHV infects all Glossina species included in the current and previous studies underscores the importance of taking appropriate measures to ensure that field-derived biological material to establish new tsetse colonies for mass rearing is free of GpSGHV infections. A positive note on virus management in tsetse mass rearing is that it is highly likely that the key GpSGHV genes critical for the virus infections and transmission are conserved over haplotypes, implying that a common strategy can be used to mitigate virus infections in multiple tsetse species. This approach is supported by successful control of the GpSGHV using antiviral drugs, which target the viral dnapol gene [21, 47, 48]. With the potential of the evolving viral genotypes with enhanced infection and transmission dynamics in sinsect mass production facilities, the data presented herein are essential for future development of robust strategies against new GpSGHV strains. It is therefore recommended that different tsetse species should be reared in separate insectaries (or under appropriate conditions) to avoid horizontal transmission of GpSGHV from one species to another during membrane feeding.

\section{Methods}

\section{Sample collection}

Glossina flies were collected between 1994 and 1995 and between 2005 and 2015 from 29 geographical locations in eastern, southern and central African countries. The flies were collected as described by Kariithi et al., [15]. Flies from seven species were analysed in this study, i.e. G. pallidipes, G. morsitans morsitans, G. swynnertoni, G. fuscipes fuscipes, G. brevipalpis, G. palpalis palpalis and G. austeni (Table 1). The collected samples were preserved in absolute ethanol, or propylene glycol, shipped to the IPCL of the Joint FAO/IAEA Division of Nuclear Techniques in Food and Agriculture, Seibersdorf, Austria, and stored at $-20{ }^{\circ} \mathrm{C}$ until further analysis.

\section{DNA extraction, polymerase chain reaction (PCR) and gel electrophoresis}

Total DNA was extracted from whole fly bodies of 3229 individuals divided over the varies species mentioned above using the DNeasy Tissue Kit (QIAGEN Inc., Valencia, CA) following the manufacturer's instructions. PCR amplifications were performed as previously described [15]. Briefly, final reaction volumes of $25 \mu \mathrm{l}$ were used containing $12.5 \mu \mathrm{l}$ of Taq PCR Master Mix (Taq PCR Master Mix Kit, QIAGEN Inc.), $\sim 50 \mathrm{ng}$ of the isolated DNA template, $1 \mu \mathrm{l}$ of forward and reverse primers to a final concentration of $0.2 \mathrm{mM}$ per primer and $10 \mu \mathrm{l}$ of RNAse-free water. PCR products were analysed by $1.5 \%$ agarose gel electrophoresis according to standard protocols. 
Verification of the taxonomic status of tsetse species Taxonomic status of the Glossina flies, determined initially on visual identification in the field, were analysed (8/species) using the optimized molecular markers described by Augustinos et al. [17]. The markers consisted of PCR-based sequencing of the non-coding internally transcribed spacer-1 (ITS1) of the ribosomal DNA (rDNA), and on Wolbachia diagnosis. The ITS1 sequence provides differences in the PCR product lengths produced with different tsetse species. Diagnosis of Wolbachia infection was applied to further verify the tsetse species, i.e. PCR-detection for the presence or absence of this endosymbiont [49]. Laboratory tsetse flies of known taxonomic status (i.e. obtained from the IPCL) were used as positive controls during the species identification by the above-mentioned molecular markers.

\section{Determination of GpSGHV prevalence}

To determine GpSGHV prevalence in the randomly collected tsetse samples, PCRs were performed to amplify a partial sequence of two conserved viral genes, odv-e66 (SGHV005) and dnapol (SGHV079) using sets of primers as described by Abd-Alla et al. [5]. Samples were considered virus-infected if the expected PCR products of at least one of the two viral genes were detected (Table 4). The Glossina species microsatellite GpCAG133 was used to control the quality of the extracted DNA and the PCR amplifications.

\section{PCR product purification and sequencing}

To determine GpSGHV genetic variation in the virus positive flies (marked with asterisks (*) in Table 1), three putative open reading frames (ORFs) and two VNTRs were selected, based on the differences in the genomes of the virus from Uganda (GpSGHV-Uga; Accession Number: EF568108) and from Ethiopia (GpSGHV-Eth; Accession Number: KU050077) [11]. The selected ORFs were; SGHV009, SGHV010, SGHV038, and the GpSGHV VNTR-1 and VNTR-2 (corresponding to R1 and R2) loci as described in Abd-Alla et al. [19]. PCRs were performed as described above with primers shown in Table 4. The PCR amplification conditions for ORFs SGHV009, SGHV010 and SGHV038 were, 5 min at $95^{\circ} \mathrm{C}$, 35 cycles of $94{ }^{\circ} \mathrm{C}$ for $45 \mathrm{~s}, 60{ }^{\circ} \mathrm{C}$ for $45 \mathrm{~s}$ and $72{ }^{\circ} \mathrm{C}$ for

Table 4 List of primers used in the study

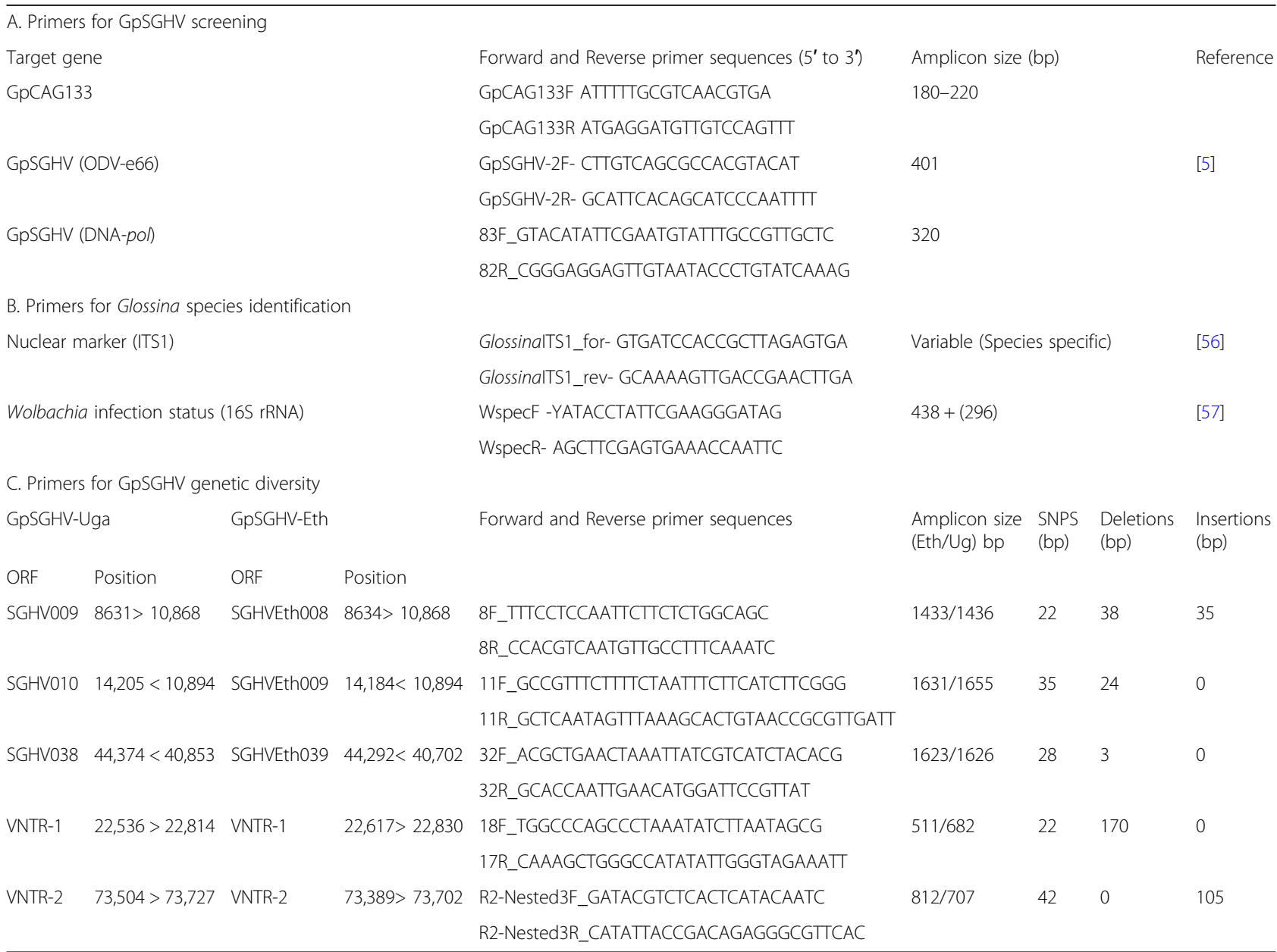

The expected PCR product and the variations (SNPs, deletions or insertion) between the Ugandan and Ethiopian strains are indicated 
$2 \mathrm{~min}$, then $72{ }^{\circ} \mathrm{C}$ for $10 \mathrm{~min}$. PCR cycling conditions for the VNTR- 1 and VNTR-2 were, 5 min at $95{ }^{\circ} \mathrm{C}$, 35 cycles of $94{ }^{\circ} \mathrm{C}$ for $45 \mathrm{~s}, 45{ }^{\circ} \mathrm{C}$ for $45 \mathrm{~s}$ and $72{ }^{\circ} \mathrm{C}$ for $1 \mathrm{~min}$, followed by $72{ }^{\circ} \mathrm{C}$ for $10 \mathrm{~min}$. PCR products were subsequently purified using the QIAquick PCR purification Kit (Qiagen, Valencia, CA), and sequenced from both ends by the Sanger method (Eurofins Genomics, Ebersberg, Germany) using their respective primer sets.

\section{Phylogenetic analysis}

DNA sequence reads from the sequenced PCR products were assembled and aligned using the SeqMan Pro (Lasergene 14, DNASTAR, Inc.). Only sequences with good quality reads in the chromatograms were further analysed. Single nucleotide polymorphisms (SNPs), deletions or insertions of sequences were determined based on the GpSGHV-Uga genome as the reference. The Open Reading Frame Finder platform (https:// www.ncbi.nlm.nih.gov/orffinder/) was used to identify the ORF of SGHV009, SGHV010 and SGHV038 viral genes for all the samples. The nucleotide sequences were translated using the BioEdit program [50] to identify the synonymous and non-synonymous mutations. Both nucleotide and the translated amino acid sequences of individual viral genes were used to determine phylogenetic relationships amongst the GpSGHV haplotypes infecting the seven Glossina species. Here, we define a haplotype as a population of closely related genetic variants resulting from mutations events. The sequences were aligned and trimmed using ClustalW on MEGA6 using default settings [51]. Concatenated sequences of the three genes and the two VNTRs were used for phylogenetic analyses using Maximum-Likelihood (ML) based on the General Time Reversible (TR) model with gamma distributed rates [52] with 1000 bootstrap replications. Samples that could not be sequenced in all the selected genes and VNTRs were marked with '?' to indicate missing sequence in the concatenated sequence alignment. It should be noted that attempts to PCR-amplify these samples using flanking primer sets also failed. To determine the number of GpSGHV haplotypes present amongst the Glossina populations, samples presenting the same sequence were categorised as a single haplotype.

\section{Estimation of gene genealogies}

The Arlequin software version 3.5 [53] was used to compare the genetic differences of the haplotypes and their relationships (mutation events between the haplotypes). The Arlequin program produced connection lengths which were equal to the number of mutational differences (single nucleotide polymorphisms and deletions/ insertions) between two haplotypes, here named as mutation events. The deletions or insertions that occurred as a block of repeat unit in the VNTRs sequences were interpreted as one connection length (mutation event). The Arlequin output files were used to visualize the haplotype network on the HapStar program version 0.7 [54]. Hapstar uses a spring model algorithm by automatic repulsion of disconnected haplotype branch nodes and the connected ones to an optimal format. The haplotype network was then exported as a scalable vector graphics (SVG) and loaded into Inkscape graphics editor software v 0.92.1 [55] for additional text, colours and patterns.

\section{Additional files}

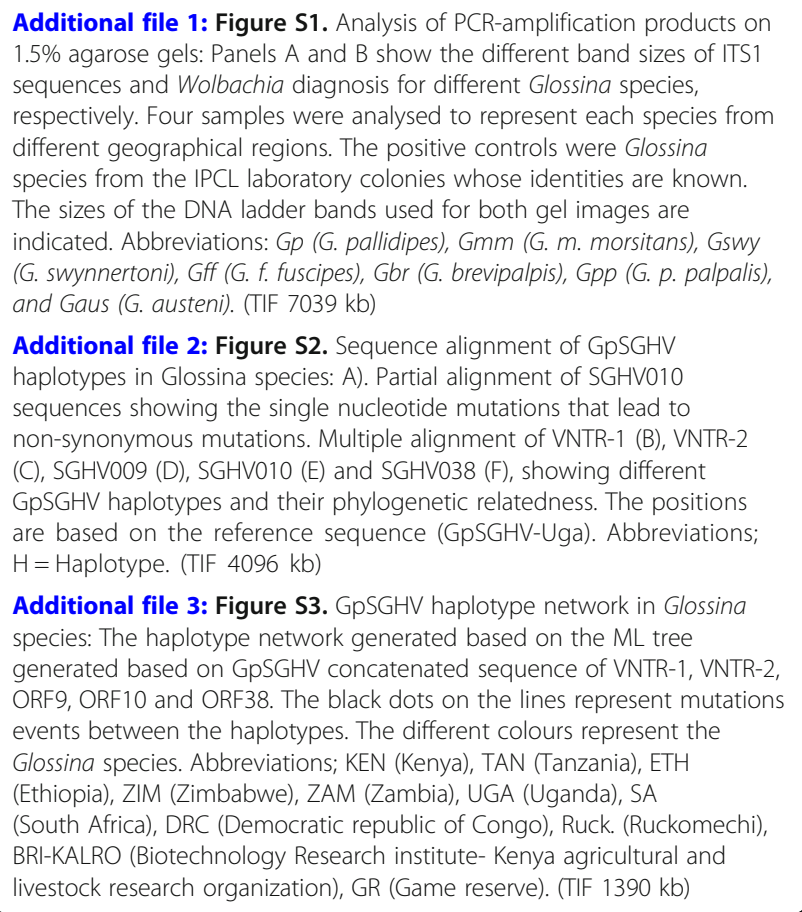

Abbreviations

AW-IPM: Area-wide integrated pest management; GpSGHV: Glossina pallidipes salivary gland hypertrophy virus; H: Haplotype; IAPV: Israeli Acute Paralysis Virus; IPCL: Insect Pest Control Laboratory; ITS1: Internal transcribed space 1; MdSGHV: Musca domestica salivary gland hypertrophy virus; ML: Maximum likelihood; SGH: Salivary gland hypertrophy; SIT: Sterile insect technique; SNP: Single nucleotide polymorphism; VNTRs: Variable number tandem repeat regions; WNV: West Nile virus

\section{Acknowledgements \\ The authors acknowledge Hasim Mohamed of IPCL for technical assistance in sample handling, preparations and data management. Lucas Tanui of the Kenya Agricultural and Livestock Research Organization (KALRO) is also acknowledged for mapping the GPS coordinates of the sampling sites.}

\section{Funding}

This work was financially supported by the Joint FAO/IAEA, division of Nuclear Techniques in Food and Agriculture, Vienna, Austria (CRP \#D42015), and by Wageningen University (WU).

Both FAO/IAEA Division and WU participated in the design of the study including collection, analysis, and interpretation of data as well as in writing the manuscript. 


\section{Availability of data and materials}

Materials described in the manuscript, including all relevant raw data, will be freely available to any scientist wishing to use them for non-commercial purposes upon request via e-mail with the corresponding author.

\section{About this supplement}

This article has been published as part of BMC Microbiology Volume 18 Supplement 1, 2018: Enhancing Vector Refractoriness to Trypanosome Infection. The full contents of the supplement are available online at https:// bmcmicrobiol.biomedcentral.com/articles/supplements/volume-18supplement-1.

\section{Authors' contributions}

AMMA, AGP, VJM, VOMM: designed, supervised the research and writing of the manuscript. MIK, AM, AGP, AMMA: conducted the experiments, collected and analysed data and prepared the figs. MIK, AGP, MJBV, KHM, VJM, VOMM, AMMA: participated in the writing of the manuscript. All authors have read and revised the manuscript and approved the final version.

\section{Ethics approval and consent to participate}

Not applicable.

\section{Consent for publication}

Not applicable.

\section{Competing interests}

The authors declare that they have no competing interests.

\section{Publisher's Note}

Springer Nature remains neutral with regard to jurisdictional claims in published maps and institutional affiliations.

\section{Author details}

'Insect Pest Control Laboratory, Joint FAO/IAEA Programme of Nuclear Techniques in Food and Agriculture, International Atomic Energy Agency, Vienna International Centre, P.O. Box 100 1400, Vienna, Austria. ${ }^{2}$ Laboratory of Virology, Wageningen University and Research, 6708, PB, Wageningen, The Netherlands. ${ }^{3}$ Biotechnology Research Institute, Kenya Agricultural and Livestock Research Organization, P.O Box 57811, Loresho, Nairobi, Kenya. ${ }^{4}$ Insect Genetics Unit, Nuclear Science and Technology Research Institute, Karaj, Iran.

\section{Published: 23 November 2018}

\section{References}

1. Vreysen MJB, Saleh KM, Lancelot R, Bouyer J. Factory tsetse flies must behave like wild flies: a prerequisite for the sterile insect technique. PLoS Negl Trop Dis. 2011;5(2):e907.

2. Vreysen MJB, Saleh KM, Ali MY, Abdulla AM, Zhu Z-R, Juma KG, Dyck VA, Msangi AR, Mkonyi PA, Feldmann HU. Glossina austeni (Diptera: Glossinidae) eradicated on the island of Unguja, Zanzibar, using the sterile insect technique. J Econ Entomol. 2000;93(1):123-35.

3. Alemu T, Kapitano B, Mekonnen S, Aboset G, Kiflom M, Bancha B, Woldeyes G, Bekele K, Feldmann U. Area-wide control of tsetse and trypanosomosis: Ethiopian experience in the southern Rift Valley. In: Vreysen MJB, Robinson AS, Hendrichs J, editors. Area-wide control of insect pests: from research to field implementation. Dordrecht: Springer Netherlands; 2007. p. 325-35.

4. Gouli V, Gouli S, Marcelino J. Principal group of infectious insect diseases. In: Common infectious diseases of insects in culture: diagnostic and prophylactic methods. Dordrecht: Springer Netherlands; 2011. p. 7-42.

5. Abd-Alla A, Bossin H, Cousserans F, Parker A, Bergoin M, Robinson A. Development of a non-destructive PCR method for detection of the salivary gland hypertrophy virus (SGHV) in tsetse flies. J Virol Methods. 2007;139(2):143-9.

6. Abd-Alla A, Parker A, Vreysen M, Bergoin M. Tsetse salivary gland hypertrophy virus: hope or hindrance for tsetse control? PLoS Negl Trop Dis. 2011;5(8):e1220.

7. Ugelvig LV, Cremer S. Effects of social immunity and unicoloniality on host-parasite interactions in invasive insect societies. Funct Ecol. 2012; 26(6):1300-12.
8. López-Uribe MM, Sconiers WB, Frank SD, Dunn RR, Tarpy DR. Reduced cellular immune response in social insect lineages. Biol Lett. 2016;12(3): 20150984.

9. Lazzaro BP, Little TJ. Immunity in a variable world. Philos Trans R. Soc Lond B Biol Sci. 2009;364(1513):15-26.

10. Siva-Jothy MT, Moret $Y$, Rolff J. Insect immunity: an evolutionary ecology perspective. In: Simpson SJ, editor. Adv. In Insect Phys, vol. 32. Academic Press; 2005. p. 1-48.

11. Abd-Alla AMM, Kariithi HM, Cousserans F, Parker NJ, Ince IA, Scully ED, Boeren S, Geib SM, Mekonnen S, Vlak JM, et al. Comprehensive annotation of Glossina pallidipes salivary gland hypertrophy virus from Ethiopian tsetse flies: a proteogenomics approach. J Gen Virol. 2016;97(4):1010-31.

12. Kariithi $H$, van Oers M, Vlak J, Vreysen M, Parker A, Abd-Alla A. Virology, epidemiology and pathology of Glossina hytrosavirus, and its control prospects in laboratory colonies of the tsetse fly, Glossina pallidipes (Diptera; Glossinidae). Insects. 2013;4(3):287-319.

13. Sang RC, Jura WGZO, Otieno $L H$, Tukei PM, Mwangi RW. Effects of tsetse DNA virus infection on the survival of a host fly, Glossina morsitans centralis (Diptera; Glossinidae). J Invertebr Pathol. 1997:69(3):253-60.

14. Kariithi HM, Yao X, Yu F, Teal PE, Verhoeven CP, Boucias DG. Responses of the housefly, Musca domestica, to the hytrosavirus replication: impacts on host's vitellogenesis and immunity. Front Microbiol. 2017;8:583.

15. Kariithi HM, Ahmadi M, Parker AG, Franz G, Ros VID, Haq I, Elashry AM, Vlak $J M$, Bergoin $M$, Vreysen MJB, et al. Prevalence and genetic variation of salivary gland hypertrophy virus in wild populations of the tsetse fly Glossina pallidipes from southern and eastern Africa. J Invertebr Pathol. 2013; 112(Supplement 1):S123-32.

16. Grubaugh ND, Weger-Lucarelli J, Murrieta RA, Fauver JR, Garcia-Luna SM, Prasad AN, Black Iv WC, Ebel GD. Genetic drift during systemic arbovirus infection of mosquito vectors leads to decreased relative fitness during host switching. Cell Host Microbe. 2016;19(4):481-92.

17. Augustinos AA, Meki IK, Saridaki A, Demirbas G, Tsiamis G, van Oers MM, Vreysen MJB, Parker AG, Abd-Alla AMM, K B: contributing to the resolution of taxonomic puzzles: multiple molecular tools and development of protocols for the accurate identification of tsetse species. BMC Microbiol. 2018. In press.

18. Doudoumis V, Alam U, Aksoy E, Abd-Alla AMM, Tsiamis G, Brelsfoard C, Aksoy $\mathrm{S}$, Bourtzis K. Tsetse-Wolbachia symbiosis: comes of age and has great potential for pest and disease control. J Invertebr Pathol. 2013;112(0):S94-S103.

19. Abd-Alla AMM, Cousserans F, Parker AG, Jehle JA, Parker NJ, Vlak JM, Robinson AS, Bergoin M. Genome analysis of a Glossina pallidipes salivary gland hypertrophy virus reveals a novel, large, double-stranded circular DNA virus. J Virol. 2008:82(9):4595-611.

20. Hudson RR. Gene genealogies and the coalescent process. Oxford Surv Evol Biol. 1990;7:1-44.

21. Abd-Alla AMM, Kariithi HM, Mohamed AH, Lapiz E, Parker AG, Vreysen MJB. Managing hytrosavirus infections in Glossina pallidipes colonies: feeding regime affects the prevalence of salivary gland hypertrophy syndrome. PLoS One. 2013;8(5):e61875.

22. Parrish CR, Holmes EC, Morens DM, Park E-C, Burke DS, Calisher CH, Laughlin CA, Saif $L$, Daszak P. Cross-species virus transmission and the emergence of new epidemic diseases. Microbiol Mol Biol Rev. 2008;72(3):457-70.

23. Whitnall ABM. The trypanosome infections of Glossina pallidipes in the Umfolosi game reserve, Zululand. (final report.). Onderstepoort J. Vet. Sci. Anim Indonesia. 1934:2(1):7-21.

24. Jenni L, Steiger R. Virus like particles of Glossina fuscipes fuscipes Newst. 1910. Acta Trop. 1974:31(2):177-80

25. Jenni L, Steiger RF. Virus like particles in the tsetse fly, Glossina morsitan sspp. Preliminary results. Rev Suisse Zool. 1974;81:663-6.

26. Jaenson TGT. Virus-like rods associated with salivary gland hyperplasia in tsetse, Glossina pallidipes. Trans R Soc Trop Med Hyg. 1978;72(3):234-8.

27. Shaw MK, Moloo SK. Virus-like particles in rickettsia within the midgut epithelial cells of Glossina morsitans centralis and Glossina brevipalpis. J Invertebr Pathol. 1993:61(2):162-6.

28. Mauck K, Bosque-Pérez NA, Eigenbrode SD, De Moraes CM, Mescher MC. Transmission mechanisms shape pathogen effects on host-vector interactions: evidence from plant viruses. Funct Ecol. 2012;26(5):1162-75.

29. Duffy S, Shackelton LA, Holmes EC. Rates of evolutionary change in viruses: patterns and determinants. Nat Rev Genet. 2008;9(4):267-76.

30. Abd-Alla AMM, Kariithi HM, Parker AG, Robinson AS, Kiflom M, Bergoin M, Vreysen MJB. Dynamics of the salivary gland hypertrophy virus in laboratory 
colonies of Glossina pallidipes (Diptera: Glossinidae). Virus Res. 2010;150(1-2): 103-10.

31. Gemayel R, Cho J, Boeynaems S, Verstrepen KJ. Beyond junk-variable tandem repeats as facilitators of rapid evolution of regulatory and coding sequences. Genes. 2012;3(3):461-80.

32. Schlötterer C. Evolutionary dynamics of microsatellite DNA. Chromosoma. 2000;109(6):365-71.

33. van Belkum A, Scherer S, van Alphen L, Verbrugh H: Short-sequence DNA repeats in prokaryotic genomes. Microbiol Mol Biol Rev 1998, 62(2):275-293.

34. Kariithi HM, van Lent JWM, Boeren S, Abd-Alla AMM, Ince IA, van Oers MM, Vlak JM. Correlation between structure, protein composition, morphogenesis and cytopathology of Glossina pallidipes salivary gland hypertrophy virus. J. Gen. Virol. 2013;94(1):193-208.

35. Mocaski ES. Introduction: definition and classification of the human herpesviruses, Comparative analysis of herpesvirus-common proteins. In: Biology, Therapy and Immunoprophylaxis, vol. 44-58. Cambridge: Cambridge University Press; 2007.

36. Shackelton LA, Holmes EC. The evolution of large DNA viruses: combining genomic information of viruses and their hosts. Trends Microbiol. 2004; 12(10):458-65.

37. Boucias DG, Kariithi HM, Bourtzis K, Schneider DI, Kelley K, Miller WJ, Parker AG, Abd-Alla AMM. Transgenerational transmission of the Glossina pallidipes hytrosavirus depends on the presence of a functional symbiome. PLoS One. 2013;8(4):e61150

38. Kapun M, Nolte V, Flatt T, Schlötterer C. Host range and specificity of the Drosophila C virus. PLoS One. 2010;5(8):e12421.

39. Clavijo G, Williams T, Muñoz D, Caballero P, López-Ferber M. Mixed genotype transmission bodies and virions contribute to the maintenance of diversity in an insect virus. Proc R Soc Lond B Biol Sci. 2010;277(1683):943-51.

40. Kariithi HM, Ince IA, Boeren S, Abd-Alla AMM, Parker AG, Aksoy S, Vlak JM, van Oers MM. The salivary secretome of the tsetse fly Glossina pallidipes (Diptera: Glossinidae) infected by salivary gland hypertrophy virus. PLoS Negl Trop Dis. 2011;5(11):e1371.

41. Van Den Abbeele J, Caljon G, De Ridder K, De Baetselier P, Coosemans M. Trypanosoma brucei modifies the tsetse salivary composition, altering the fly feeding behavior that favors parasite transmission. PLoS Pathog. 2010;6(6): e1000926.

42. Spath J. Feeding patterns of three sympatric tsetse species (Glossina spp.) (Diptera: Glossinidae) in the preforest zone of cote d'Ivoire. Acta Trop. 2000; 75:109-18.

43. Caljon G, De Ridder K, De Baetselier P, Coosemans M, Van Den Abbeele J. Identification of a tsetse fly salivary protein with dual inhibitory action on human platelet aggregation. PLoS One. 2010;5(3):e9671.

44. Lietze V-U, Sims KR, Salem TZ, Geden CJ, Boucias DG. Transmission of MdSGHV among adult house flies, Musca domestica (Diptera: Muscidae), occurs via oral secretions and excreta. J Invertebr Pathol. 2009;101(1):49-55.

45. Geden CJ, Lietze V-U, Boucias DG. Seasonal prevalence and transmission of salivary gland hypertrophy virus of house flies (Diptera: Muscidae). J Med Entomol. 2008:45(1):42-51.

46. Singh $\mathrm{R}$, Levitt AL, Rajotte EG, Holmes EC, Ostiguy N, vanEngelsdorp $D$, Lipkin Wl, dePamphilis CW, Toth AL, Cox-Foster DL. RNA viruses in hymenopteran pollinators: evidence of inter-taxa virus transmission via pollen and potential impact on non-Apis hymenopteran species. PLoS One. 2010;5(12):e14357.

47. Abd-Alla AMM, Adun H, Parker AG, Vreysen MJB, Bergoin M. The antiviral drug valacyclovir successfully suppresses salivary gland hypertrophy virus (SGHV) in laboratory colonies of Glossina pallidipes. PLoS One. 2012;7(6):e38417.

48. Abd-Alla AMM, Marin C, Parker AG, Vreysen MJB. Antiviral drug valacyclovir treatment combined with a clean feeding system enhances the suppression of salivary gland hypertrophy in laboratory colonies of Glossina pallidipes. Parasit \& Vectors. 2014;7:214.

49. Schneider DI, Garschall Kl, Parker AG, Abd-Alla AMM, Miller WJ. Global Wolbachia prevalence, titer fluctuations and their potential of causing cytoplasmic incompatibilities in tsetse flies and hybrids of Glossina morsitans subgroup species. J Invertebr Pathol. 2013;112(Suppl 1):S104-15.

50. Hall T. BioEdit: an important software for molecular biology. GERF Bulletin of Biosciences. 2011;2:30-61.

51. Tamura K, Stecher G, Peterson D, Filipski A, Kumar S. MEGA6: molecular evolutionary genetics analysis version 6.0. Mol Biol Evol. 2013;30(12):2725-9.

52. Rodríguez F, Oliver JL, Marín A, Medina JR. The general stochastic model of nucleotide substitution. J Theor Biol. 1990;142(4):485-501.
53. Excoffier L, Laval G, Schneider S. Arlequin (version 3.0): an integrated software package for population genetics data analysis. Evol Bioinforma. 2005;1:47-50

54. Teacher AGF, Griffiths DJ. HapStar: automated haplotype network layout and visualization. Mol Ecol Resour. 2011;11(1):151-3.

55. Bah T: Inkscape: guide to a vector drawing program: prentice hall press; 2007

56. Dyer NA, Lawton SP, Ravel S, Choi KS, Lehane MJ, Robinson AS, Okedi LM, Hall MJ, Solano P, Donnelly MJ. Molecular phylogenetics of tsetse flies (Diptera: Glossinidae) based on mitochondrial (COI, 16S, ND2) and nuclear ribosomal DNA sequences, with an emphasis on the palpalis group. Mol Phylogenet Evol. 2008:49.

57. Doudoumis V, Tsiamis G, Wamwiri F, Brelsfoard C, Alam U, Aksoy E, Dalaperas S, Abd-Alla A, Ouma J, Takac P, et al. Detection and characterization of Wolbachia infections in laboratory and natural populations of different species of tsetse flies (genus Glossina). BMC Microbiol. 2012;12(Suppl 1):S3.

\section{Ready to submit your research? Choose BMC and benefit from:}

- fast, convenient online submission

- thorough peer review by experienced researchers in your field

- rapid publication on acceptance

- support for research data, including large and complex data types

- gold Open Access which fosters wider collaboration and increased citations

- maximum visibility for your research: over $100 \mathrm{M}$ website views per year

At $\mathrm{BMC}$, research is always in progress.

Learn more biomedcentral.com/submissions 